\title{
Influence of Solid Loading on the Granulation of 3Y-TZP Powder by Two-Fluid Spray Drying
}

\author{
Hyeongdo Jeong and Jong Kook Lee ${ }^{\dagger}$ \\ Department of Materials Science and Engineering, Chosun University, Gwangju 61452, Korea \\ (Received March 6, 2018; Revised April 19, May 28, 2018; Accepted May 29, 2018)
}

\begin{abstract}
The influence of solid loading in the slurry composition on the morphology of 3Y-TZP granules fabricated by two-fluid spray drying was investigated for solid contents varying between $30 \mathrm{wt} \%$ and $50 \mathrm{wt} \%$. The resulting $3 \mathrm{Y}$-TZP granules showed a spherelike shape with diameters of $40-70 \mu \mathrm{m}$. However, a donut-like shape and a few cracks were observed on the granule surfaces fabricated using the slurry with $50 \mathrm{wt} \%$ solid content. The green density after cold isostatic pressing at $200 \mathrm{MPa}$ was $2.1-2.2 \mathrm{~g} /$ $\mathrm{cm}^{3}$, and a homogeneous fracture surface was obtained by complete destruction of granules. After sintering at $1500^{\circ} \mathrm{C}$ for $2 \mathrm{~h}$, all specimens had relative densities of 96.2 - 98.3\%. With increasing solid content, the relative density decreased from $98.3 \%$ to $96.2 \%$, but the grain size increased from $0.3 \mu \mathrm{m}$ to $0.6 \mu \mathrm{m}$. Highly sinterable zirconia granule powder could be obtained by controlling the slurry composition.
\end{abstract}

Key words : Zirconia, Granule morphology, Spray drying, Sintered density

\section{Introduction}

$I_{\text {s }}^{\mathrm{s}}$ is important to obtain homogeneous and dense green compacts for the application of 3Y-TZP dental implant ceramics. Inhomogeneous and porous green compacts may induce large shrinkage during sintering, thus leadings to size and shape mismatches in the final product. For mismatched products obtained after sintering, additive machining is necessary, which results in high production cost because it is difficult to machine brittle ceramics like zirconia ceramics. Therefore, homogeneous shrinkages must be precisely controlled during the forming and sintering pro(esses. ${ }^{1)}$

Most zirconia green compacts are prepared by pressing, injection molding, extrusion, gel casting, or slip casting. Among these forming methods, the pressing method is simple and widely used in ceramic processing. ${ }^{2-4)}$ The microstructure and density of green bodies fabricated by pressing are dependent on the powder properties, e.g., the particle size and shape, agglomeration, additive agent, etc. To obtain a homogeneous green body, granular powder is primarily used in the pressing method. Superior granule powders have characteristics of a spherical shape, uniform size, smooth surface, and weak intergranular bonding.5)

Spray drying is a typical method to produce spherical granules. In this process, a homogeneous suspension of ceramic powder in a liquid solvent is prepared to obtain globular granules with an additive dispersant. Using a

\footnotetext{
Corresponding author: Jong Kook Lee

E-mail : jklee@chosun.ac.kr

Tel : +82-62-230-7202 Fax : +82-62-232-2474
}

nozzle or a rotating disk, a droplet of slurry is sprayed into a chamber heated at a temperature of $100-250^{\circ} \mathrm{C}{ }^{6-8)}$ The sprayed droplets are dried rapidly by heating the air, to form granules with various shapes, including spherical, hollow, donut-shaped, and needle-like. Excellent granules have homogeneous size and spherical shape, but should not be hollow. They also have uniform particle arrangement and weak intergranular bonding, because homogeneous green compacts can be obtained by complete fracturing of granules under compaction pressure. Therefore, superior granular powder induces homogeneous green compact and highly sintered body. ${ }^{9)}$

Granule properties are influenced by the slurry viscosity, chemical composition, particle size distribution, and spraydrying conditions. In this study, we investigated the effect of the solid content of zirconia slurry on the formation of granules, and the powder properties. Zirconia slurry for spray drying was prepared from nano-sized zirconia powder, isopropyl alcohol, binder (PVB, polyvinyl butyral), plasticizer (PEG 4000, polyethylene glycol), and a dispersing agent (Triton X-100). Sphere-like granules were manufactured by spray drying with two fluid nozzles, and the powder properties were characterized. ${ }^{10-13)}$ Using granule powders and pressing, we fabricated green compacts and sintered bodies.

\section{Experimental Procedure}

The fluidal slurry for spray drying was prepared by mixing nanoscale 3Y-TZP powder with isopropyl alcohol (IPA) as a solvent. First, a dispersion agent (Triton X-100) was diluted in IPA to obtain a stable slurry with homogeneous 
Table 1. Detailed Slurry Composition for Two-Fluid Spray Drying

\begin{tabular}{ccc}
\hline Component & Type & Amount \\
\hline 3Y-TZP powder & Primary component & $30,40,50 \mathrm{wt} \%$ \\
Isopropyl alcohol & Solvent & $46.7-66.7 \mathrm{wt} \%$ \\
Triton X-100 & Dispersant & $1 \mathrm{wt} \%$ \\
Polyethylene glycol & Plasticizer & $2 \mathrm{wt} \%$ \\
4000 & Binder & $1.3 \mathrm{wt} \%$ \\
Polyvinyl butyral & & \\
\hline
\end{tabular}

dispersion; subsequently, a plasticizer (PEG 4000, polyethylene glycol 4,000) and binder (PVB, polyvinyl butyral) were dissolved in an aqueous solution with vigorous stirring at 80 ${ }^{\circ} \mathrm{C}$. ${ }^{14-16)}$ The detailed slurry composition for two-fluid spray drying is shown in Table 1 . In the slurry preparation process, the solid content of the 3Y-TZP powder was fixed at 30, 40 , and $50 \mathrm{wt} \%$.

After mixing the 3Y-TZP powder and additives, the $\mathrm{pH}$ was adjusted to 11.5 by the addition of aqueous ammonia $\left(\mathrm{NH}_{4} \mathrm{OH}\right)$ to obtain low-viscosity slurry, which reduced the problem of nozzle clogging, and induced spherical droplet formation. ${ }^{17-19)}$ To sustain the homogeneity and stability of the zirconia slurry, it was milled in a ball mill for 1 day. After milling, it was completed by ultrasonic dispersion for $30 \mathrm{~min}$. The ceramic slurry treated with ultrasonic dispersion was enhanced in terms of aging, anti-foaming, lessagglomeration behaviors, and slurry stability. ${ }^{20)}$

Spray drying for the granulation of zirconia slurry was performed by a two-fluid nozzle dryer (SD-Basic, Lab Plant, UK). The detailed processing conditions for spray drying are shown in Table 2. After spray drying, the additive agents were burned out of the formed granules by calcination at $400^{\circ} \mathrm{C}$ for $2 \mathrm{~h}$. This temperature was determined by differential thermal and thermogravimetric analyses (DTATGA). The flowchart for this experimental procedure is shown in Fig. 1.

The specific surface area and morphology of the 3Y-TZP granules were analyzed by the Brunauer-Emmett-Teller (BET) method and field-emission scanning electron microscopy (FE-SEM). To confirm the fracture and formability of the granules under molding pressure, the green body fracture surface was observed by FE-SEM after cold isostatic pressing at $200 \mathrm{MPa}$ for $5 \mathrm{~min}$. The perfect destruction

Table 2. Detailed Processing Parameters for Spray Drying of 3Y-TZP Granulation

\begin{tabular}{cc}
\hline Parameter & Condition \\
\hline Inlet temperature & $200^{\circ} \mathrm{C}$ \\
Outlet temperature & $110-120^{\circ} \mathrm{C}$ \\
Chamber pressure & $1.5 \mathrm{bar}$ \\
Nozzle type & Two-fluid nozzle \\
Nozzle size & $0.5 \mathrm{~mm}$ \\
Feeding rate & $10-20 \mathrm{ml} / \mathrm{min}$ \\
\hline
\end{tabular}

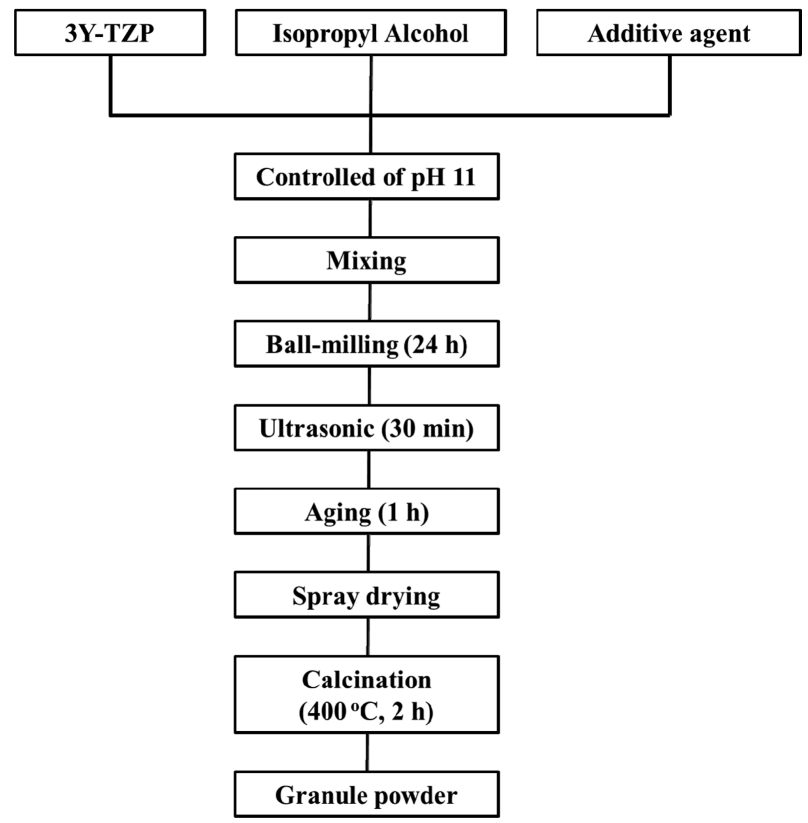

Fig. 1. Flowchart for the granulation of 3Y-TZP powder.

of granules is essential to obtain a homogeneous microstructure of green compacts and dense 3Y-TZP ceramics after sintering. The apparent density of the densified specimens sintered at $1500^{\circ} \mathrm{C}$ for $2 \mathrm{~h}$ was measured by the Archimedes method. The microstructure of the sintered compacts was observed by SEM after polishing and thermal etching.

\section{Results and Discussion}

The morphology and microstructure of the granules are dependent on the slurry composition and spray drying conditions. One important factor is the slurry viscosity, which is influenced by solid loading, $\mathrm{pH}$, and additive content, and affects the droplet morphology obtained using the two-fluid nozzles. In addition to slurry viscosity, the droplet morphology (size distribution, sphericity, type) is dependent on the nozzle type, feeding rate, and additives (composition and content).

In this experiment, the slurry viscosity was measured for various solid contents, as shown in Table 3. By a preliminary experiment, the optimal slurry $\mathrm{pH}$ and additives were determined, as described above. Table 3 shows that the slurry viscosity varied from $55 \mathrm{cP}$ to $171 \mathrm{cP}$ as the solid loading of the 3Y-TZP powder varied from $30 \mathrm{wt} \%$ to $50 \mathrm{wt} \%$. The droplet formation from slurry and the workability of spray drying (nozzle clogging, cleaning) were sensitive to the slurry viscosity. The formation of spherical droplets was difficult in the slurry with low viscosity. In contrast, nozzle clogging frequently occurred in high-viscosity slurry.

Generally, the granule size and morphology are also dependent on the slurry viscosity, feeding rate of the slurry, 
Table 3. Slurry and Granule Properties Depending on Zirconia Solid Content

\begin{tabular}{cccc}
\hline $\begin{array}{c}\text { Solid } \\
\text { content }\end{array}$ & $\begin{array}{c}\text { Slurry } \\
\text { viscosity } \\
(\mathrm{cP})\end{array}$ & $\begin{array}{c}\text { Specific surface } \\
\text { area } \\
\left(\mathrm{m}^{2} / \mathrm{g}\right)\end{array}$ & $\begin{array}{c}\text { Green } \\
\text { density } \\
\left(\mathrm{g} / \mathrm{cm}^{3}\right)\end{array}$ \\
\hline $30 \mathrm{wt} \%$ & 55 & 5.6 & 2.1 \\
$40 \mathrm{wt} \%$ & 85 & 5.3 & 2.2 \\
$50 \mathrm{wt} \%$ & 171 & 5.1 & 2.2 \\
\hline
\end{tabular}

air pressure, and drying conditions, which are related to the droplet size and morphology, and must be precisely controlled to obtain spherical granules. Therefore, for the formation of high-quality granules, it is very important to control the slurry viscosity by adjusting the $\mathrm{pH}$ and addi-

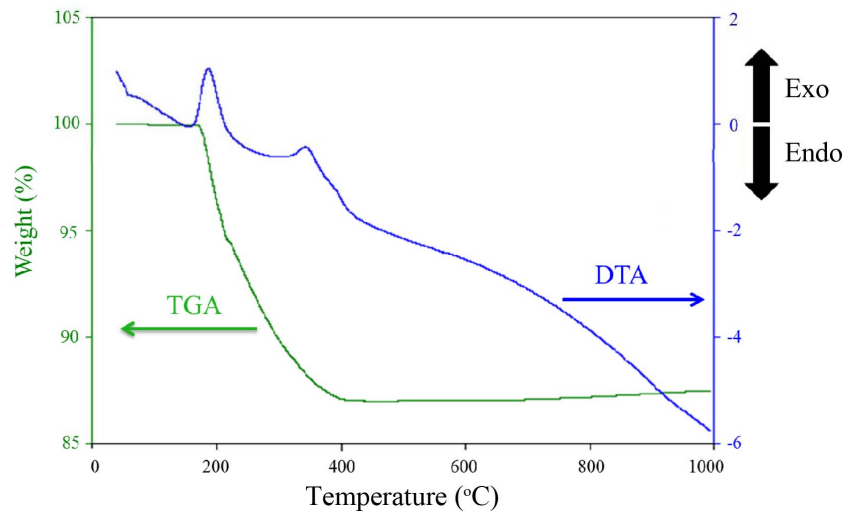

Fig. 2. DTA-TGA analysis of granule powder after spray drying.
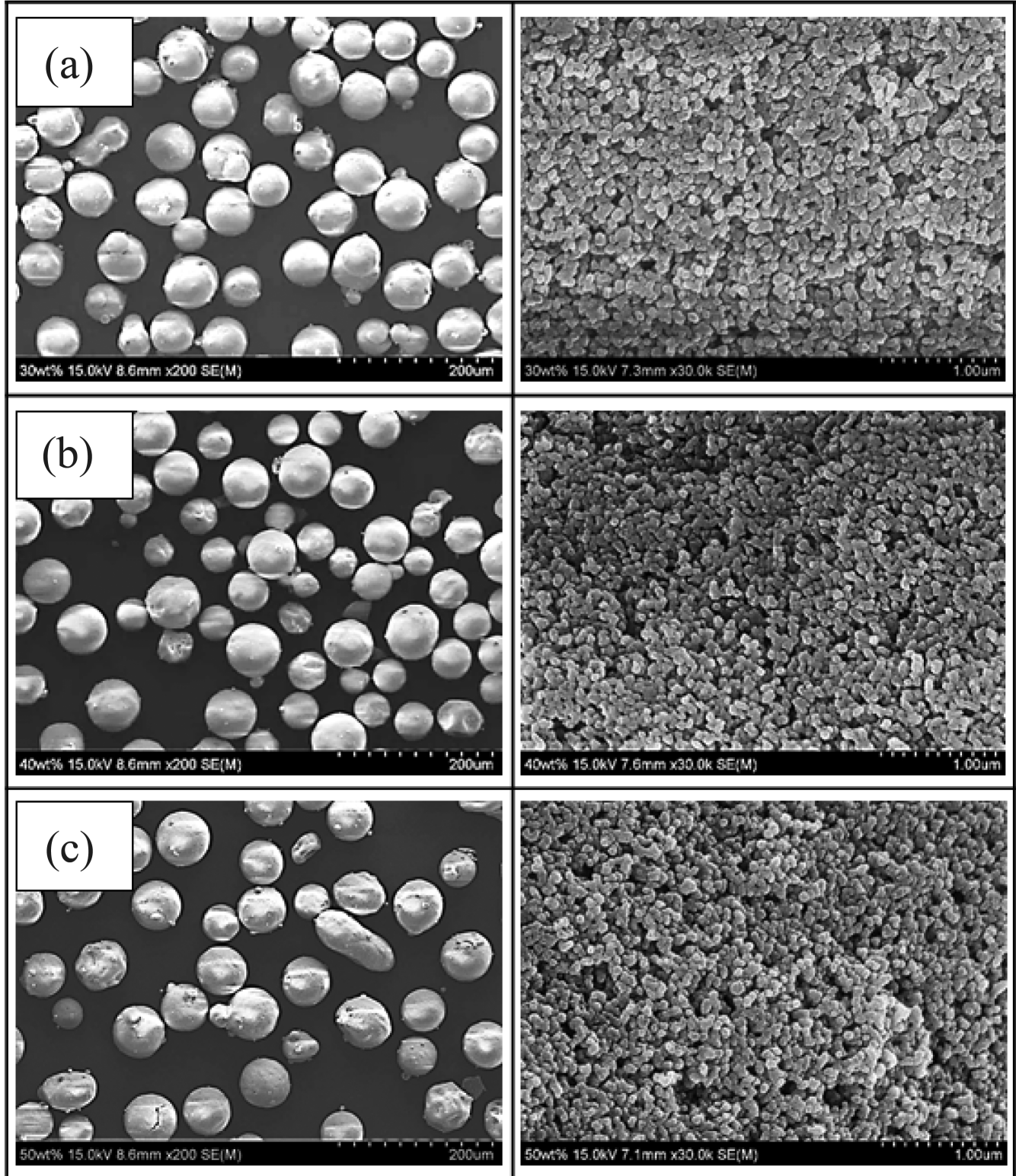

Fig. 3. Granule powder from solid contents of (a) $30 \mathrm{wt} \%$, (b) $40 \mathrm{wt} \%$, and (c) $50 \mathrm{wt} \%$. 
tives, such as dispersants.

To determine the burnout temperature of the additive agent, the thermal behavior of the granule powder was investigated by DTA-TGA analysis at a temperature range of $25-1000{ }^{\circ} \mathrm{C}$ (Fig. 2). An exothermic reaction accompanied by weight loss was observed between $200-300^{\circ} \mathrm{C}$, which was due to the decomposition of PEG 4000. A secondary exothermic peak appeared at temperatures of $350-400^{\circ} \mathrm{C}$ from the burning of PVB, as shown in the curve. The total weight loss was approximately $13 \%$, as observed from the decomposition of the additive agent and residual water.

The specific surface area of the prepared granule powder (Table 3), measured by the BET method, is a parameter to describe the powder activity, formability, and sinterability. It depends on the initial solid content of the slurry. As the solid content in the slurry increased from $30 \mathrm{wt} \%$ to $50 \mathrm{wt} \%$, the specific surface area decreased slightly from $5.6 \mathrm{~m}^{2} / \mathrm{g}$ to $5.1 \mathrm{~m}^{2} / \mathrm{g}$, owing to the evaporation of water and formation of a highly porous granule structure.

Figure 3 shows the spherical granule morphologies and surface microstructures as a function of solid content. The zirconia granule powders after spray drying had a spherical shape with diameters of $40-70 \mu \mathrm{m}$. Donut-like shapes and a few cracks were occasionally observed on the granule surface fabricated from slurry containing $50 \mathrm{wt} \%$ solid due to the high viscosity, which induced an inhomogeneous granule structure and surface cracks during drying of the droplet in the chamber. FE-SEM images showed a homogeneous particle arrangement and uniform microstructure in all granules, indicating weak intragranular bonding.

Weak bonding between particles in the granule structure is one of the primary parameters to evaluate the granule powder, because it affects the forming homogeneity, green microstructure, and density. To obtain homogeneous microstructure of the green body, easily broken granules under the molding pressure are required. Therefore, only granule conditions of weak intragranular bonding between particles could be obtained. The SEM image (Fig. 4) of the fracture surface of the green body manufactured by isostatic pressing showed the complete destruction and the filling of intergranular pores by primary particles. The green density after cold isostatic pressing at $200 \mathrm{MPa}$ indicated $2.1-2.2 \mathrm{~g} / \mathrm{cm}^{3}$, as shown in Table 3, showing a slight difference with respect to the solid content. Regardless of the solid content in the slurry, all the fracture surfaces had homogeneous microstructures without pores or cracks. Occasionally, poorquality granules, with strong intragranular bonding between particles were found to have high green density with inhomogeneous microstructure due to the non-fractured granules, despite the isostatic pressing. However, this induced poor sintered density owing to the formation of lenticular cracks and large pores.

The relative densities of the specimens sintered at $1500^{\circ} \mathrm{C}$ for $2 \mathrm{~h}$ decreased from $98.3 \%$ to $96.2 \%$ upon increasing initial solid content from $30 \mathrm{wt} \%$ to $50 \mathrm{wt} \%$. This suggested that different granule properties due to the variation in

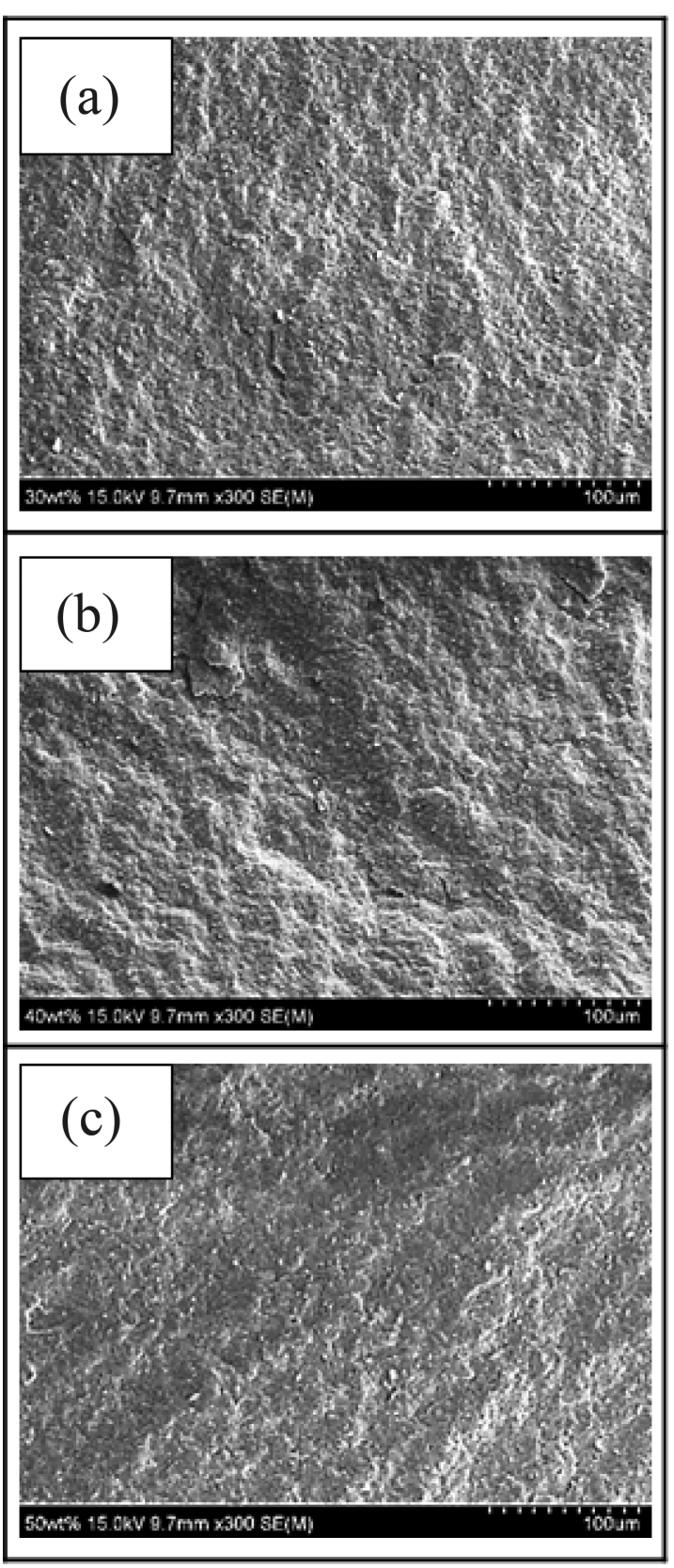

Fig. 4. Fracture surfaces of green body prepared with granules from slurries of (a) $30 \mathrm{wt} \%$, (b) $40 \mathrm{wt} \%$, and 50 wt\% solid contents.

solid content of the slurry affected the green microstructure and the sintered properties. The highest sintered density for the 3Y-TZP granules was found with solid loading of $30 \mathrm{wt} \%$ in slurry. As described earlier, low specific surface area, poor sphericity (donut-like shapes) and a few surface cracks were observed in spray-dried granules prepared from high solid-loading slurry owing to the high viscosity and the formation of macroscopic flocs, which induced microstructural inhomogeneities and resulted in low sintered density. ${ }^{19)}$ Occasionally, high solid loading induced a dense granule shell and resulted in donut or apple shaped 
granules. $^{21-23)}$ Strict powder processing and granulation are necessary to obtain highly sintered specimens, including the starting chemicals, particle agglomeration, and the specific surface and type of the additive system. In addition, the granule morphology (size, shape, bonding force) is also important to obtain a homogeneous microstructure of green compacts, and weak intra-granular bonding. ${ }^{17,24-27)}$ Especially, a donut-like morphology and large-sized of granules from a high solid-loading slurry might be affect the microstructure of the green compact and sintered body. The donut-like and large granules induced heterogeneous green microstructures by the partially fractured granules and large inter-granular pores, and finally enhanced the grain growth and porosity of the sintered body by a local intra-granular densification. ${ }^{28-30}$

The microstructure of the specimen sintered at $1500^{\circ} \mathrm{C}$ for
$2 \mathrm{~h}$ was observed on the polished and thermally etched surface (Fig. 5). All the specimens showed homogeneous microstructures, but the grain size was dependent on the solid content in slurry. With increasing solid content in the slurry, the grain size increased from $0.3 \mu \mathrm{m}$ to $0.6 \mu \mathrm{m}$. The sintered compact fabricated from the slurry with a low solid content of $30 \mathrm{wt} \%$ had a grain size of less than $0.3 \mu \mathrm{m}$; however, in the specimen fabricated from the slurry with a solid content above $40 \mathrm{wt} \%$, the grain size was greater than 0.6 $\mu \mathrm{m}$. Large grains due to rapid grain growth formed inhomogeneous granules properties and green microstructures. As described previously, donut-like granules and some surface cracks were observed on the granule surfaces manufactured from slurry with high solid content. Consequently, highly sinterable zirconia granule powders could only be obtained
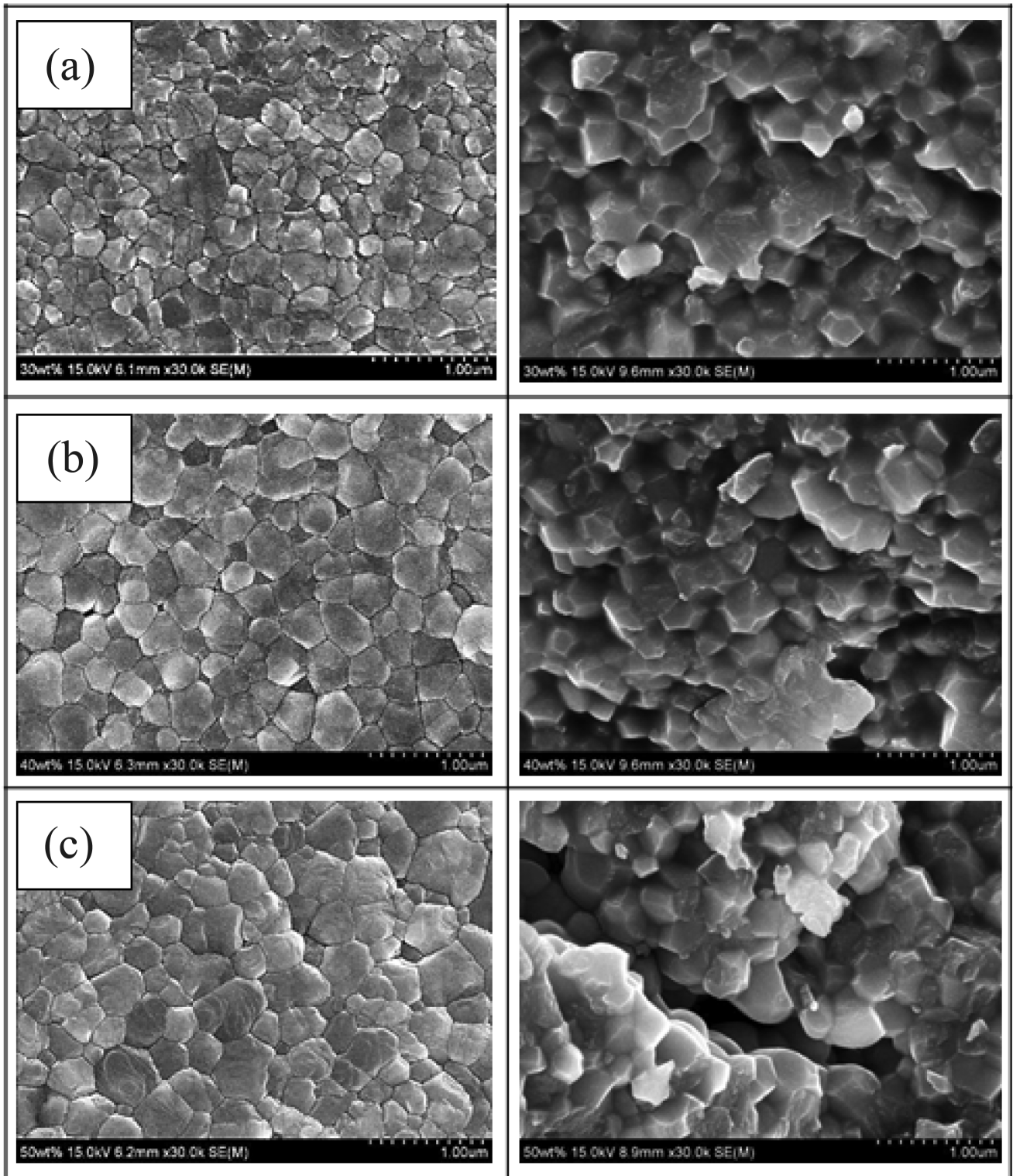

Fig. 5. Polished and fractured surfaces of 3Y-TZP sintered specimens from solid contents of (a) 30 wt\%, (b) 40 wt\%, and (c) 50 wt\%. 
from a precisely controlled slurry composition and processing condition in spray drying.

\section{Conclusions}

Spherical 3Y-TZP granule powders were fabricated by spray drying, and the influence of solid content on the granules, formation, and sintered properties was investigated. Three kinds of stable zirconia slurries were prepared using 3Y-TZP powder with different solid contents (30 wt\%, $40 \mathrm{wt} \%$, $50 \mathrm{wt} \%)$, solvents, and additive agents. The solid content in zirconia slurry affected the granules, formation, and sintered properties.

The 3Y-TZP granule powder with a sphere-like shape was obtained by spray drying, and its diameter $(40-70 \mu \mathrm{m})$ and morphology were dependent on the solid content in the slurry. Most granules showed homogeneous particle arrangements on the granule surface, indicating a uniform microstructure and weak intra-granular bonding. High viscosity and low dispersion were observed in the slurry with high solid content, and non-spherical droplets were formed during spray drying. Many donut-like shapes were observed in the granule powder, and a few cracks were found on the granule surface fabricated from the slurry with high solid content.

From the observation of the fractured surfaces on the green compacts after pressing by low magnification, all fracture surfaces were observed to contain homogeneous microstructures without pores and cracks. The sintered properties were dependent on the solid content in the slurry. Specimens fabricated from the low-solid-content slurry had a highly sintered density and small grain microstructures (below $0.3 \mu \mathrm{m}$ ), and poor-quality specimens with a low sintered density and large grain size (above $0.3 \mu \mathrm{m}$ ) were fabricated from the slurry with a high solid content. In conclusion, the solid content in zirconia slurry had a significant effect on the granule morphology, homogeneity of the green microstructure, and sintering properties. In this experiment, among three kinds of zirconia slurries, the optimal solid content for spray drying of zirconia was found to be $30 \mathrm{wt} \%$, based on the investigation of granule shape, formability, sintering density, and microstructure.

\section{Acknowledgments}

This study was supported by the research fund from Chosun University, 2017.

\section{REFERENCES}

1. I. Denry and J. A. Holloway, "Ceramics for Dental Applications: A Review," Materials, 3 [1] 351-68 (2013).

2. S. P. Passos, B. Linke, P. W. Major, and J. A. Nychka, "The Effect of Air-Abrasion and Heat Treatment on the Fracture Behavior of Y-TZP," Dent. Mater., 31 [9] 1011-21 (2015).
3. M. V. Swain, "Impact of Oral Fluids on Dental Ceramics: What is the Clinical Relevance?," Dent. Mater., 30 [1] 3342 (2014).

4. H. T. Kim, J. H. Yang, J. B. Lee, and S. H. Kim, "The Effect of Low Temperature Aging on the Mechanical Property \& Phase Stability of Y-TZP Ceramics," J. Adv. Prosthodont., 1 [3] 113-17 (2009).

5. C. Piconi and G. Maccauro, "Zirconia as a Ceramic Biomaterial," Biomaterials, 20 [1] 1-25 (1999).

6. X. Guo, "On the Degradation of Zirconia Ceramics during Low-Temperature Annealing in Water or Water Vapor," J. Phys. Chem. Solids, 60 [4] 539-46 (1999).

7. B. D. Flinn, A. J. Raigrodski, A. Singh, and L. A. Mancl, "Effect of Hydrothermal Degradation on Three Types of Zirconias for Dental Application," J. Prosthet. Dent., 112 [6] 1377-84 (2014).

8. I. Denry and J. R. Kelly, "State of the Art of Zirconia for Dental Applications," Dent. Mater., 24 [3] 299-307 (2008).

9. G. Bertrand, C. Filiatre, and C. Coddet, "Spray-Dried Ceramic Powders: A Quantitative Correlation between Slurry Characteristics and Shapes of the Granules," Chem. Eng. Sci., 60 [1] 95-102 (2005).

10. M. Keuper, C. Berthold, and K. G. Nickel, "Long-Time Aging in $3 \mathrm{~mol} \%$ Yttria-Stabilized Tetragonal Zirconia Polycrystals at Human Body Temperature," Acta Biomater., 10 [2] 951-59 (2014).

11. J. S. Choi and Y. M. Kong, "A Case Study on Sintering Characteristics of Yttria Stabilized Zirconia Powder Prepared by Two-Fluid Spray Drying," J. Korean Ceram. Soc., 53 [3] 332-37 (2016).

12. S. J. Lukasiewicz, "Spray-Drying Ceramic Powders," J. Am. Ceram. Soc., 72 [4] 617-24 (1989).

13. Y. N. Ko, S. M. Lee, J. H. Lee, J. K. Lee, and Y. C. Kang, "Sintering Characteristics of Nano-Sized Yttria-Stabilized Zirconia Powders Prepared by Spray Pyrolysis," J. Ceram. Proc. Res., 13 [4] 405-8 (2012).

14. T. K. Gupta, F. F. Lange, and J. H. Bechtold, "Effect of Stress-Induced Phase Transformation on the Properties of Polycrystalline Zirconia Containing Metastable Tetragonal Phase,” J. Mater. Sci., 13 [7] 1464-70 (1978).

15. F. F. Lange, H. Shubert, and M. Ruhle," Effects of Attrition Milling and Post-Sintering Heat Treatment on Fabrication, Microstructure and Properties of Transformation Toughened $\mathrm{ZrO}_{2}$," J. Mater. Sci., 21 [3] 768-74 (1986).

16. R. C. Garvie, "The Occurrence of Metastable Tetragonal Zirconia as a Crystalite Size Effect," J. Phys. Chem. Soc., 69 [4] 1238-43 (1965).

17. W. J. Walker and J. S. Reed, "Influence of Slurry Parameters on the Characteristics of Spray-Dried Granules," J. Am. Ceram. Soc., 82 [7] 1711-19 (1999).

18. J. A. Muñoz-Tabares, E. Jimenez-Piqué, J. Reyes-Gasga, and M. Anglada, "Microstructural Changes in Ground 3Y-TZP and Their Effect on Mechanical Properties," Acta Mater., 59 [17] 6670-83 (2011).

19. V. Naglieri, D. Gutknecht, V. Garnier, P. Palmero, J. Chevalier, and L. Montanaro., "Optimized Slurries for Spray Drying: Different Approaches to Obtain Homogeneous and Deformable Alumina-Zirconia Granules," Materials, 6 [11] 5382-97 (2013). 
20. B. P. C. Raghupathy and J. G. P. Binner, "Spray Granulation of Nanometric Zirconia Particles," J. Am. Ceram. Soc., 94 [1] 42-8 (2011).

21. L. Zhang, Y. Li, X. Li, H. Yang, X. Qiao, T. Zhou, Z. Wang, J. Zhang, and D. Tang, "Characterization of Spray Granulated Nd: YAG Particles for Transparent Ceramics," J. Alloys Compd., 639 244-51 (2015).

22. J. H. Kim and J. K. Lee, "Effect of Drying Method on the Synthesis of Yttria-Stabilized Zirconia Powders by CoPrecipitation," J. Nanosci. Nanotech., 16 [11] 11457-59 (2016).

23. A. Stunda-Zujeva, Z. Irbe, and L. Berzina-Cimdina, "Controlling the Morphology of Ceramic and Composite Powders Obtained via Spray Drying - A Review," Ceram. Int., 43 [15] 11543-51 (2017).

24. D. J. Kim and J. Y. Jung, "Granule Performance of Zirconia/Alumina Composite Powders Spray-Dried Using Polyvinyl Pyrrolidone Binder," J. Eur. Ceram. Soc., 27 [10] 3177-82 (2007).

25. M. I. Zainuddin, S. Tanaka, R. Furushima, and K. Uematsu, "Correlation between Slurry Properties and Structures and Properties of Granules," J. Eur. Ceram. Soc., 30 [16]
3291-96 (2010).

26. K. Somton, K. Dateraksa, D. Atong, and R. Mccuiston, "The Effect of Granule Morphology and Composition on the Compaction Behavior and Mechanical Properties of 92\% Alumina Spray Dried Granules,” J. Met., Mater. Miner., 22 [2] 41-7 (2012).

27. W. J. Walker, J. S. Reed, and S. K. Verma, "Influence of Granule Character on Strength and Weibull Modulus of Sintered Alumina," J. Am. Ceram. Soc., 82 [1] 50-6 (1999).

28. H. D. Jeong, J. W. Shin, and J. K. Lee, "Characterization of Commercial 3Y-TZP Nanopowders and Their Sintered Properties," J. Nanosci. Nanotechnol., 17 [10] 7584-88 (2017).

29. W. F. M. Groot Zevert, A. J. A. Winnubst, G. S. A. M. Theunissen, and A. J. Burggraaf, "Powder Preparation and Compaction Behaviour of Fine-Grained Y-TZP," J. Mater. Sci., 25 [8] 3449-55 (1989).

30. P. M. Souto, R. R. Menezes, and R. H. G. A. Kiminami, "Sintering of Commercial Mulite Powder: Effect of $\mathrm{MgO}$ Dopant," J. Mater. Process. Technol., 209 [1] 548-53 (2009) 